Short Communication

\title{
A split-mouth randomized clinical trial to evaluate the effect of local and systemic administration of vitamin $C$ on extraction wound healing
}

\author{
Sarinya Yingcharoenthana ${ }^{1)}$, Ruchanee Ampornaramveth ${ }^{2)}$, Keskanya Subbalekha ${ }^{1)}$, Phonkit Sinpitaksakul ${ }^{3)}$, \\ and Paksinee Kamolratanakul ${ }^{1)}$
}

${ }^{1)}$ Department of Oral and Maxillofacial Surgery, Faculty of Dentistry, Chulalongkorn University, Bangkok, Thailand

${ }^{2}$ Department of Microbiology, Faculty of Dentistry, Chulalongkorn University, Bangkok, Thailand

${ }^{3)}$ Department of Radiology, Faculty of Dentistry, Chulalongkorn University, Bangkok, Thailand

(Received September 29, 2020; Accepted November 27, 2020)

\begin{abstract}
A split-mouth single-blind randomized-controlled clinical trial study was designed to investigate the effect of local and systemic vitamin $\mathrm{C}$ administration on extraction wound healing. Thirty patients who underwent bilateral premolar extraction were randomly divided into three group pairs; group 1: control and systemic administration (Con/CSA), group 2: control and a combination of local and systemic administration (Con/ CLSA), and group 3: systemic and a combination of local and systemic administration (CSA/CLSA). The vitamin C (600 mg) was taken by swallowing (systemic administration) or slow oral dissolution (combined local and systemic administration). The socket size and radiographic density were evaluated immediately after extraction, and 7 days and 21 days later. The results demonstrated that the percentage radiographic density of new bone formation in the socket did not differ significantly within each group. However, in the CSA and CLSA group there was an improvement of soft tissue healing based in terms of socket depth reduction at 21 days after extraction compared with the control $(P<0.05)$.
\end{abstract}

Keywords; local administration, systemic administration, tooth extraction, vitamin $\mathrm{C}$, wound healing

\section{Introduction}

One factor that impacts negatively on wound healing is deficiency of certain nutrients, such as vitamin C [1]. Vitamin C participates in collagen synthesis, secretion, maturation, and degradation [2], and importantly functions in bone development, regulating osteoblast proliferation [3].

A previous in vitro study has demonstrated that local application of vitamin $\mathrm{C}$ promoted fibroblast migration and stimulated gene expression related to fibroblast wound healing activity [4]. Clinically, vitamin C passes across the oral mucosa via lipid membranes by simple diffusion [5]. However, the effect of local administration of vitamin $\mathrm{C}$ on oral wound healing has not been well investigated. The aim of the present study was to investigate the efficacy of local and systemic administration of vitamin $\mathrm{C}$ on the healing of tooth extraction wounds based on soft tissue and bone remodeling.

\section{Materials and Methods}

This study was conducted between September 2019 and April 2020 at the Faculty of Dentistry, Chulalongkorn University, Thailand. It was approved by the Ethics Review Committee for Research Involving Human Research Subjects, Health Science Group, Chulalongkorn University, Thailand (HREC-DCU 2019-060). The criteria for inclusion of patients in the study were that they should be healthy, 15-35 years old, and presenting for bilateral premolar extraction as part of an orthodontic treatment plan. Patients

Correspondence to Dr. Paksinee Kamolratanakul, Department of Oral and Maxillofacial Surgery, Faculty of Dentistry, Chulalongkorn University, 34 Thanon Henri Dunant Wang Mai, Pathum Wan District, Bangkok 10330, Thailand

Fax:+662-2188581 E-mail: orepaksinee@yahoo.com

J-STAGE Advance Publication: February 17, 2021

Color figures can be viewed in the online issue at J-STAGE.

doi.org/10.2334/josnusd.20-0515

DN/JST.JSTAGE/josnusd/20-0515 who unable to take vitamin $\mathrm{C}$ at least 2 times/day, or who missed taking vitamin $\mathrm{C}$ more than 4 times during study period were excluded. The mean and standard deviation obtained from a pilot study was used to calculate the sample size, which was set at 30 .

Vitamin $\mathrm{C}$ tablets were taken either systemically by swallowing, or slowly dissolved in the mouth to achieve a combination of both local and systemic administration. The patients received two 100 -mg vitamin $\mathrm{C}$ tablets each time, 3 times/day for 14 days. The control group did not receive any vitamin $\mathrm{C}$. In this split mouth study, the patients were randomly divided into three groups: group 1: control and systemic administration (Con/CSA), group 2: control and a combination of local and systemic administration (Con/CLSA), and group 3: systemic administration and a combination of local and systemic administration (CSA/CLSA). Atraumatic tooth extraction was performed and the time for the procedure was recorded. At the first visit, the tooth and the intervention were determined randomly. Twenty-one days after extraction, the contralateral tooth was extracted and the other intervention was prescribed. The patients were instructed to avoid a high vitamin $\mathrm{C}$ diet. Any missing dose of vitamin $\mathrm{C}$ had to be recorded.

\section{Postoperative evaluation}

The socket size was evaluated by two blinded examiners. The buccolingual and mesio-distal socket widths were measured using a caliper (Fig. 1A) and the socket depth was measured with a periodontal probe (Fig. 1B). The socket was measured immediately after extraction, and then 7 days and 21 days later. The results were calculated as the percentage reduction in socket size using the following formula:

$\frac{\left[\text { Measurement }_{(\text {Immediate/ Day } 7 \text { post-extraction) }}-\text { Measurement }_{(\text {Day } 7 / \text { Day } 21 \text { post-extraction) }}\right] \times 100}{\text { Measurement }}$

Bone healing was evaluated by a blinded examiner and assessed from a periapical radiograph with reproducible position using the individual silicone bite index. The same X-ray machine (Kodak 2200 Intraoral X-ray System, Carestream Health Inc., Rochester, NY, USA) and the same digital intraoral imaging scanner (KaVo Scan eXam One, PaloDEx Group Oy, Tuusula, Finland) were used. The radiographs were taken immediately and 21 days after extraction. ImageJ version 1.52a (Oracle America Inc., Redwood City, CA, USA) was used to evaluate radiographic density. The radiographic density of the socket was averaged from 3 defined locations: the cervical, middle, and apical third in the center of the socket. The radiographic density of the socket was normalized to either the average radiographic density of the adjacent alveolar bone or root dentin (cervical, middle, and apical third) (Fig. 1C) in order to reduce errors caused by radiographic image contrast [6]. The percentage radiographic density of bone in the socket was calculated as:

Average radiographic bone density in the socket $\times 100$ Average radiographic density in root dentin or alveolar bone

The difference in the percentage radiographic density of bone in the socket between the operation day and postoperative day 21 was calculated.

Statistical analyses were performed using SPSS version 22.0 (SPSS Inc., Chicago, IL, USA), and differences at $P<0.05$ were considered 


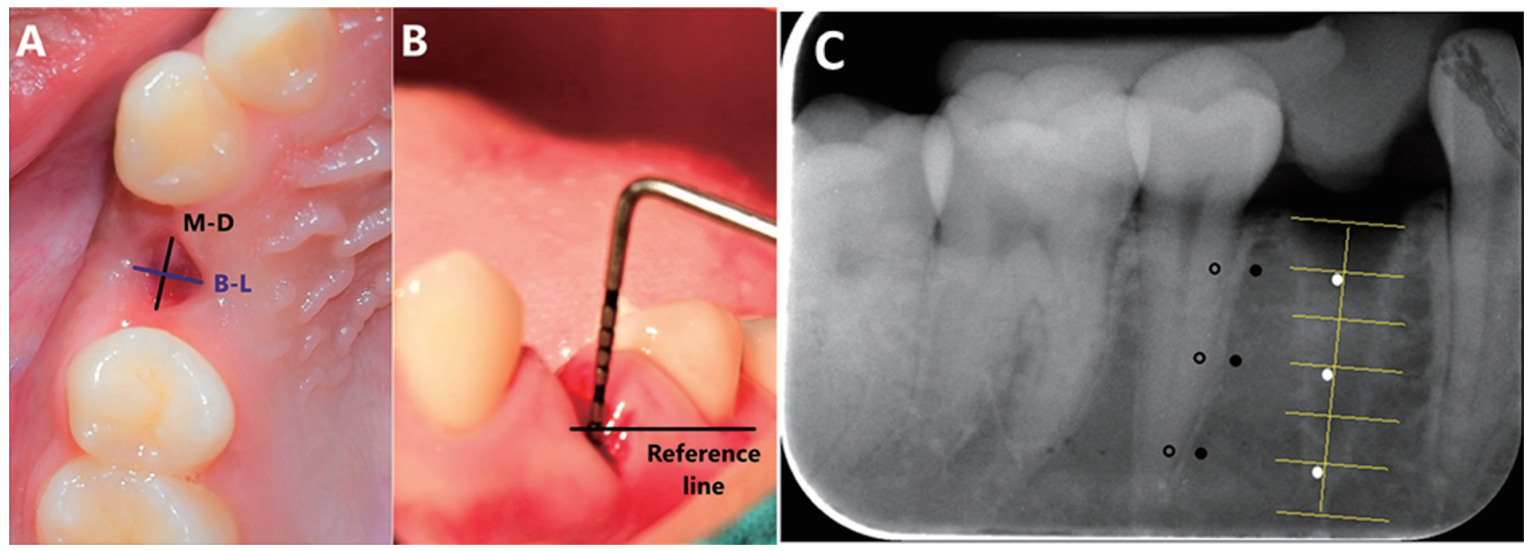

Fig. 1 Socket size and radiographic density measurement. (A) Measuring the bucco-lingual width (blue line) and mesio-distal width (black line) with a caliper. (B) Measuring the socket depth with a periodontal probe using the cervical gingival margin of the adjacent tooth as the reference point. (C) Radiographic image indicating the three locations in the mid-socket that were assessed for radiographic density (white dots), the three locations in root dentin (unfilled dots), and the alveolar bone (black dots) that were used as references.

Table 1 Demographic data for the patients

\begin{tabular}{|c|c|c|c|c|c|}
\hline Demographic data & All & Con/CSA group & Con/CLSA group & CSA/CLSA group & $P$-value \\
\hline $\operatorname{Sex}(n[\%])$ & & & & & 0.621 \\
\hline - Male & $9(30 \%)$ & $3(30 \%)$ & $4(40 \%)$ & $2(20 \%)$ & \\
\hline - Female & $21(70 \%)$ & $7(70 \%)$ & $6(60 \%)$ & $8(80 \%)$ & \\
\hline - Mean \pm SD & $20.07 \pm 2.66$ & $20.90 \pm 2.47$ & $19.30 \pm 2.54$ & $20.00 \pm 2.98$ & \\
\hline - Range & $15-24$ & $17-24$ & $16-24$ & $15-23$ & \\
\hline Extraction site $(n[\%])$ & & & & & 0.875 \\
\hline
\end{tabular}

significant. Chi-squared test was used to compare sex and extraction site. One-way ANOVA and Bonferroni test were used to compare ages among the groups (Shapiro-Wilk test, $P=0.132$ and Levene's test, $P=0.774$ ). Wilcoxon signed-rank test was used to determine the amount of missed vitamin $\mathrm{C}$ doses, operation time, percentage reduction of socket size, and percentage radiographic density of formed bone in the socket.

\section{Results}

The data from 30 patients were analyzed. The demographic data for the study patients are presented in Table 1 . There were no significant differences in sex, age, or extraction site among the 3 groups, suggesting that the related factors were distributed equally in all of the paired groups. The operation time for the 1st extraction site (median [IQR], 2.50 [2.03-4.45] $\mathrm{min}$ ) and that for the 2nd extraction site (median [IQR], 2.54 [1.70-4.08] $\min )$ in each patient did not differ significantly between the sides $(P=$ 0.520). The amount of missed vitamin $C$ doses between the two extractions in the CSA/CLSA group and the CLSA subgroup (median [IQR], 2.50 $[0.50-3.75]$ ) was significantly greater than in the CSA subgroup (median [IQR], 0.50 [0-1.75]) $(P=0.026)$.

The soft tissue healing and socket size in the various groups were compared. The percentage reduction in socket depth differed significantly within the Con/CSA and Con/CLSA groups. The percentage reduction of socket depth in the period immediately after and 21 days after extraction in the Con/CSA group and CSA subgroup was significantly higher than in the control group $(P=0.018)$. The percentage reduction of socket depth in the period between 7 and 21 days after extraction in the Con/CLSA group and CLSA subgroup was significantly higher than in the control group $(P$ $=0.028)$ (Table 2).

The percentage radiographic density of bone formed in the socket did not differ significantly within each group. However, the change in percentage radiographic density in the period from immediately after to 21 days after extraction in the subgroups that received vitamin $\mathrm{C}$ was higher than in the control group (Table 3).

\section{Discussion}

The present study investigated the effects of two different routes of vitamin $\mathrm{C}$ administration: systemic and a combination of local and systemic. The combination of local and systemic administration of vitamin $\mathrm{C}$ resulted in better overall socket healing. Local administration of vitamin $\mathrm{C}$ may have a more active effect because vitamin $\mathrm{C}$ can be absorbed directly across the oral mucosa [5].

The mean percentage reduction of socket size in the combined local and systemic administration subgroup was higher than that in the systemic administration subgroup in all three dimensions. Soft tissue healing in terms of socket depth reduction was significantly improved by both systemic and combined local and systemic administration of vitamin $\mathrm{C}$. These results suggest that vitamin $\mathrm{C}$ promotes healing of granulation tissue at the bottom of the extraction socket and connective tissue, which consists of a collagen network, resulting in a decrease of socket depth. In the present study, the percentage reduction in socket depth was significantly higher than in the control at 21 days post-extraction. The connective tissue healing time corresponded with a previous study which found that vitamin $\mathrm{C}$ administration accelerated extraction socket healing at approximately 21 days [7].

A histological study of bone healing in the early weeks after human tooth extraction demonstrated that bone formation in the socket began at 10 days after extraction [8]. In the present study, the newly formed bone in the sockets that received vitamin $\mathrm{C}$ tended to be higher than in the control, but no significant differences in radiographic density were evident at 21 days post-extraction. Vitamin C-regulated bone remodeling may require differences in dose and/or the duration of treatment. Therefore, an extended study period may be needed in order to properly evaluate bone formation in healing tooth sockets.

This study had some limitations. The baseline serum level of vitamin $\mathrm{C}$ in each patient was not recorded. However, the patients were instructed to avoid a high vitamin $\mathrm{C}$ diet and to record any high vitamin $\mathrm{C}$ dietary intake on a daily basis. Therefore, the authors assumed that the serum level of vitamin $\mathrm{C}$ in each patient would have been similar during the period of study after bilateral extraction. Furthermore, this study did not use a placebo in the control group because it was not possible to produce a tablet 
Table 2 Percentage reduction of socket size in each paired group; median [IQR]

\begin{tabular}{|c|c|c|c|c|c|c|c|c|c|}
\hline & \multicolumn{3}{|c|}{ Con/CSA group } & \multicolumn{3}{|c|}{ Con/CLSA group } & \multicolumn{3}{|c|}{ CSA/CLSA group } \\
\hline & Con & CSA & $P$-value & Con & CLSA & $P$-value & CSA & CLSA & $P$-value \\
\hline \multicolumn{10}{|c|}{ Immediate-7 days } \\
\hline B-L & $\begin{array}{c}43.06 \\
{[31.25-59.38]}\end{array}$ & $\begin{array}{c}42.02 \\
{[33.82-56.25]}\end{array}$ & 0.401 & $\begin{array}{c}37.50 \\
{[34.52-40.28]}\end{array}$ & $\begin{array}{c}42.86 \\
{[27.56-50.79]}\end{array}$ & 0.612 & $\begin{array}{c}43.75 \\
{[25.98-57.14]}\end{array}$ & $\begin{array}{c}45.41 \\
{[31.15-52.88]}\end{array}$ & 0.779 \\
\hline M-D & $\begin{array}{c}42.73 \\
{[30.84-54.17]}\end{array}$ & $\begin{array}{c}42.22 \\
{[27.08-54.22]}\end{array}$ & 0.889 & $\begin{array}{c}44.44 \\
{[18.75-50]}\end{array}$ & $\begin{array}{c}50 \\
{[28.63-60]}\end{array}$ & 0.161 & $\begin{array}{c}40 \\
{[34.37-47.50]}\end{array}$ & $\begin{array}{c}45.30 \\
{[30-54.17]}\end{array}$ & 0.624 \\
\hline Depth & $\begin{array}{c}59.07 \\
{[48.22-67.31]}\end{array}$ & $\begin{array}{c}58.57 \\
{[50-71.28]}\end{array}$ & 0.327 & $\begin{array}{c}73.22 \\
{[49.04-92.31]}\end{array}$ & $\begin{array}{c}69.05 \\
{[50-77.98]}\end{array}$ & 0.314 & $\begin{array}{c}53.33 \\
{[30.77-71.28]}\end{array}$ & $\begin{array}{c}58.57 \\
{[51.93-64.29]}\end{array}$ & 0.674 \\
\hline \multicolumn{10}{|c|}{ Immediate- 21 days } \\
\hline B-L & $\begin{array}{c}52.78 \\
{[35.94-60.94]}\end{array}$ & $\begin{array}{c}55.4 \\
{[47.80-57.48]}\end{array}$ & 0.310 & $\begin{array}{c}61.11 \\
{[46.88-72.62]}\end{array}$ & $\begin{array}{c}54.55 \\
{[50-75]}\end{array}$ & 0.463 & $\begin{array}{c}55.04 \\
{[41.67-58.03]}\end{array}$ & $\begin{array}{c}55.50 \\
{[45.31-63.81]}\end{array}$ & 0.050 \\
\hline M-D & $\begin{array}{c}50.00 \\
{[38.64-55.56]}\end{array}$ & $\begin{array}{c}44.95 \\
{[35-58.66]}\end{array}$ & 0.674 & $\begin{array}{c}50 \\
{[29.17-60.99]}\end{array}$ & $\begin{array}{c}50 \\
{[40-60]}\end{array}$ & 0.401 & $\begin{array}{c}40 \\
{[34.37-57.50]}\end{array}$ & $\begin{array}{c}45.80 \\
{[41.11-54.17]}\end{array}$ & 0.362 \\
\hline Depth & $\begin{array}{c}90.55 \\
{[83.47-95]}\end{array}$ & $\begin{array}{c}100 \\
{[93.21-100]}\end{array}$ & $0.018^{*}$ & $\begin{array}{c}92.31 \\
{[83.78-95.31]}\end{array}$ & $\begin{array}{c}96.67 \\
{[91.31-100]}\end{array}$ & 0.110 & $\begin{array}{c}92.59 \\
{[84.62-100]}\end{array}$ & $\begin{array}{c}93.31 \\
{[86.16-100]}\end{array}$ & 0.345 \\
\hline \multicolumn{10}{|c|}{7 days-21 days } \\
\hline B-L & $\begin{array}{c}0 \\
{[0-18.57]}\end{array}$ & $\begin{array}{c}9.09 \\
{[0-34.38]}\end{array}$ & 0.345 & $\begin{array}{c}36.36 \\
{[25.39-52.68]}\end{array}$ & $\begin{array}{c}28.57 \\
{[10-47.92]}\end{array}$ & 0.362 & $\begin{array}{c}0 \\
{[0-34.79]}\end{array}$ & $\begin{array}{c}20.20 \\
{[0-33.33]}\end{array}$ & 0.225 \\
\hline M-D & $\begin{array}{c}0 \\
{[0-15.63]}\end{array}$ & $\begin{array}{c}0 \\
{[0-28.57]}\end{array}$ & 0.588 & $\begin{array}{c}16.67 \\
{[0-22.50]}\end{array}$ & $\begin{array}{c}0 \\
{[0-22.50]}\end{array}$ & 0.225 & $\begin{array}{c}0 \\
{[0-12.50]}\end{array}$ & $\begin{array}{c}0 \\
{[0-10.72]}\end{array}$ & 1.000 \\
\hline Depth & $\begin{array}{c}70.84 \\
{[55-90.63]}\end{array}$ & $\begin{array}{c}100 \\
{[81.25-100]}\end{array}$ & 0.091 & $\begin{array}{c}61.91 \\
{[18.75-90.63]}\end{array}$ & $\begin{array}{c}90 \\
{[67.05-100]}\end{array}$ & $0.028^{*}$ & $\begin{array}{c}85.17 \\
{[75-100]}\end{array}$ & $\begin{array}{c}84.52 \\
{[76.19-100]}\end{array}$ & 0.917 \\
\hline
\end{tabular}

B-L, bucco-lingual; M-D, mesio-distal; Con, control; CSA, systemic administration; CLSA, combination of local and systemic administration. *Indicates significant difference between subgroups $(P<0.05)$

Table 3 The change in percentage radiographic density of bone formed in the socket in the period immediately after and 21 days after tooth extraction

\begin{tabular}{|c|c|c|c|c|c|}
\hline \multirow{2}{*}{ Group } & \multirow{2}{*}{ Subgroup } & \multicolumn{2}{|c|}{ Normalized with root dentin } & \multicolumn{2}{|c|}{ Normalized with alveolar bone } \\
\hline & & Median [IQR] & $P$-value & Median [IQR] & $P$-value \\
\hline \multirow[t]{2}{*}{$\mathrm{Con} / \mathrm{CSA}$} & Con & $3.06[-2-7.34]$ & 0.401 & $1.80[0.47-7.78]$ & 0.123 \\
\hline & CSA & $6.03[1-12.61]$ & & $4.33[1.06-11.29]$ & \\
\hline \multirow[t]{2}{*}{ Con/CLSA } & Con & $2.84[-0.80-9.43]$ & 0.374 & $5.78[-1.23-8.52]$ & 0.139 \\
\hline & CLSA & $7.05[2.13-9.40]$ & & $8.28[3.04-14.53]$ & \\
\hline \multirow[t]{2}{*}{ CSA/CLSA } & CSA & 3.59 [0.66-11.97] & 0.401 & $4.93[-3.35-15.19]$ & 0.575 \\
\hline & CLSA & $3.36[-1-6.49]$ & & $5.60[-0.32-7.56]$ & \\
\hline
\end{tabular}

that mimicked the taste of the vitamin $\mathrm{C}$ tablets. Furthermore, due to the instability of vitamin $\mathrm{C}$, it was not possible to prepare a vitamin $\mathrm{C}$ mouth rinse to test the local effect. Finally, the duration of the follow-up period was limited by ongoing orthodontic treatment, and a larger sample size would be recommended for future studies.

In conclusion, both systemic and combined local and systemic administration of vitamin $\mathrm{C}$ was shown to improve soft tissue healing in terms of reduced socket depth. Therefore, use of vitamin $\mathrm{C}$ supplement after tooth extraction is recommended to promote better soft tissue healing.

\section{Acknowledgments}

The authors thank Dr. Kevin Tompkins for manuscript proofreading.

\section{Conflict of interest}

None.

\section{References}

1. Guo S, Dipietro LA (2010) Factors affecting wound healing. J Dent Res 89, 219-229.

2. Anderson B (2005) Nutrition and wound healing: the necessity of assessment. Br J Community Nurs $14,30-38$.

3. Aghajanian P, Hall S, Wongworawat MD, Mohan S (2015) The roles and mechanisms of actions of vitamin C in bone: new developments. J Bone Miner Res 30, 1945-1955.

4. Chaitrakoonthong T, Ampornaramveth R, Kamolratanakul P (2020) Rinsing with L-ascorbic acid exhibits concentration-dependent effects on human gingival fibroblast in vitro wound healing behavior. Int J Dent 21, 4706418.

5. Sadoogh-Abasian F, Evered DF (1979) Absorption of vitamin C from the human buccal cavity. Br J Nutr 42, 15-20.

6. Jansisyanont P, Tiyapongprapan S, Chuenchompoonut V, Sangvanich P, Thunyakitpisal P (2016) The effect of acemannan sponges in post-extraction socket healing: a randomized trial. J Oral Maxillofac Surg Oral Med Pathol 28, 105-110.

7. Pinnoi C, Sa-an wong P, Nubdee S (1999) The Effect of vitamin C on human extraction wound healing a clinical study. CU Dent J 22, 145-150.

8. Boyne PJ (1966) Osseous repair of the postextraction alveolus in man. Oral Surg Oral Med Oral Pathol 21, 805-813. 